\title{
Перспективные сорта свеклы столовой на различных фонах минерального питания
}

\author{
Promising varieties of beets on various backgrounds of mineral nutrition
}

Тимакова Л.Н., Борисов В.А., Фильрозе Н.А.

\section{Аннотация}

В статье представлены результаты испытания новых отечественных сортов свеклы столовой в Московской области на различных фонах минерального питания: контроль - без удобрений, $\mathrm{N}_{120} \mathrm{P}_{60} \mathrm{~K}_{180}$ (расчетная доза) и $\mathrm{N}_{240} \mathrm{P}_{120} \mathrm{~K}_{360}$ (двойная доза). Количество удобрений рассчитывалось согласно схеме опыта по фонам питания и по процентному содержанию действующего вещества. Почва опытного участка относится к типу аллювиальных луговых, среднесуглинистая, насыщенная, влагоемкая. Погодные условия наиболее благоприятно для роста и развития растений свеклы столовой складывались в периоды вегетации 2014-2017 годов. Особенность погодных условий 2018-2019 годов - неравномерное выпадение осадков, что повлияло на время прорастания семян. Дефицит влаги в период вегетации компенсировали поливами методом дождевания, поддерживая НВ на уровне 75-80 \%. В 2014-2019 годах изучали сорта свекла столовой селекции Агрохолдинга «Поиск» для товарного производства: с округлой формой корнеплода - Креолка, Мулатка, Русская односемянная, Эфиопка; цилиндрической - Славянка; округлоплоской - Смуглянка. Урожайность корнеплодов на фоне без удобрений изменялась от 36,5 (Мулатка) до 47,9 т/га (Славянка). Внесение удобрений в рекомендуемой дозе способствовало прибавке урожая, в среднем, на 20,3\% без снижения товарности продукции. Наиболее отзывчивы на минеральные удобрения в расчетной дозе $\left(\mathrm{N}_{120} \mathrm{P}_{60} \mathrm{~K}_{180}\right)$ оказались сорта Мулатка $(+33,1 \%)$ и Смуглянка (+29\%). Внесение удвоенных доз минеральных удобрений не повлекло за собой дальнейшего увеличения урожайности культуры. Сорт Креолка показал на фоне $\left(\mathrm{N}_{240} \mathrm{P}_{120} \mathrm{~K}_{360}\right)$ наибольшую урожайность - 58,6 т/га. Выращивание свеклы столовой с применением удобрений в расчетной и удвоенной дозах уменьшает вариабельность урожайности сортов по годам.

Ключевые слова: свекла столовая, сорт, минеральные удобрения, урожайность, вариабельность.

Для цитирования: Тимакова Л.Н., Борисов В.А., Фильрозе Н.А. Перспективные сорта свеклы столовой на различных фонах минерального питания // Картофель и овощи. 2020. №4. С. 11-13. https://doi.org/10.25630/PAV.2020.87.98.002

\section{Timakova L.N., Borisov V.A., Fil'roze N.A.}

\section{Abstract}

Results of testing of new domestic cultivars in the Moscow region on various backgrounds of mineral nutrition: control (without fertilizers), $\mathrm{N}_{120} \mathrm{P}_{60} \mathrm{~K}_{180}$ (calculated dose) and $\mathrm{N}_{240} \mathrm{P}_{120} \mathrm{~K}_{360}$ (double dose) are presented. The amount of fertilizers was calculated according to the scheme of the experiment by nutrition backgrounds and by the percentage of active substance. The soil of the experimental site belongs to the type of alluvial meadow, medium-loamy, saturated, moisture-intensive. Weather conditions were most favourable for the growth and development of table beet plants during the growing season of 2014-2017. A feature of the weather conditions of 2018-2019 was uneven precipitation, which affected the time of germination of seeds. The lack of moisture during the growing season was compensated by irrigation by sprinkling, maintaining the $\mathrm{HB}$ at the level of $80-85 \%$. In 2014-2019, we studied varieties of beet of table selection of Poisk Agro Holding for commercial production: with a rounded root crop - Kreolka, Mulatka, Russkaya odnosemyannaya, Efiopka; cylindrical root crop - Slavyanka; round - Smuglyanka. The yield of root crops on the background without fertilizers varied from 36.5 (mulatto) to $47.9 \mathrm{t} / \mathrm{ha}$ (Slavyanka). Application of fertilizers in the recommended dose contributed to an increase in yield, on average, by $20.3 \%$ without reducing the marketability of products. The most responsive to mineral fertilizers in the calculated dose $\left(\mathrm{N}_{120} \mathrm{P}_{60} \mathrm{~K}_{180}\right)$ were varieties Mulatka $(+33.1 \%)$ and Smuglyanka $(+29 \%)$. The introduction of doubled doses of mineral fertilizers did not lead to a further increase in crop yield. The Creole variety showed a maximum yield of $58.6 \mathrm{t} / \mathrm{ha}$ against the background $\left(\mathrm{N}_{240} \mathrm{P}_{120} \mathrm{~K}_{360}\right)$ growing table beet with the use of fertilizers in calculated and doubled doses reduces the variability in the yield of varieties over the years.

Key words: beetroot, variety, mineral fertilizers, productivity, variability.

For citing: Timakova L.N., Borisov V.A., Fil'roze N.A. Promising varieties of beets can be found on various backgrounds of mineral nutrition. Potato and vegetables. 2020. №4. Pp. 11-13. https://doi. org/10.25630/PAV.2020.87.98.002 (In Russ.)

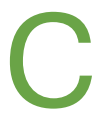

овременный рынок свеклы столовой представлен широким разнообразием сортов и гибридов, как для массового потребителя, так и для крупных производителей овощной продукции. Ежегодно Государственный реестр селекционных достижений пополняется новыми сортами свеклы столовой. Для товарного овощеводства свеклы столовой в настоящее время востребованы гибриды и сорта, отвечающие требованиям рынка, а именно сочетающие высокую урожайность и товарность корнеплодов при интенсивной технологии возделывания культуры. Но внедрение иностранного посевного материала влечет за собой и ряд проблем. Это и сохранность продукции, и качественный состав мякоти корнеплода, и увеличение степени распространенности церкоспороза и фомоза в посевах свеклы $[1,2,3]$. Внедрение в отечественное производство отечественных селекционных достижений обеспечивает продовольственную независимость РФ. В настоящее время современных сортов, способных максимально реализовать потенциал при новых индустриальных технологиях возделывания овощей, не так много. В Агрохолдинге «Поиск» созданы сорта свеклы столовой, которые успешно прошли испытания и пользуются широким спросом у крупных товаропроизводителей [4, 5]. Специально для внедрения в производство отечественных сортов, выращиваемых в ЗАО «Куликово» разработаны и изданы рекомендации по их выращиванию.

Основной элемент технологии в агрохолдингах - применение минеральных удобрений. В этом случае большое значение имеет отзывчивость сорта на виды и дозы вносимых удобрений [6]. По данным В.А. 
Борисова, различные виды удобрений и их дозы существенно влияют на товарность свеклы. Свекла столовая при применении азотных удобрений отзывается повышением выхода стандартной продукции до 94,3\%, калийных - до 95,8\% [7, 8].

Разработка и научно обоснованное совершенствование системы удобрений свеклы столовой во Всероссийском научно-исследовательском институте овощеводства - филиале ФГБНУ ФНЦО (ФГБНУ ВНИИО - филиале ФГБНУ ФНЦО) проводится в отделе земледелия и агрохимии.

Условия, материалы и методы исследований

Экспериментальная работа проводилась во ФГБНУ ВНИИО - филиале ФГБНУ ФНЦО в 2014-2019 годах. Цель исследований - изучение отзывчивости сортов на внесение различных доз удобрений. Объектом исследования служили сорта свеклы столовой с округлой формой корнеплода - Креолка, Мулатка, Русская односемянная, Эфиопка; цилиндрической - Славянка; округло-плоской Смуглянка (селекции Агрохолдинга «Поиск»), материалом - корнеплоды в технической спелости.

Почва опытного участка относится к типу аллювиальных луговых, среднесуглинистая, насыщенная, влагоемкая. Глубина пахотного слоя 27 см, глубина залегания грунтовых вод - более 2 м. Почва отличается высоким содержанием гумуса - 3,5$3,8 \%$, близкой к нейтральной реакцией солевой вытяжки - 5,5-6,1, общего азота - 0,19-0,24\%, нитратного азота - 2,0-2,8 мг/100 г, содержание подвижных форм фосфора - 17,619,1 мг/100 г, калия 7,0-8,2 мг/100 г соответственно. По совокупности физико-химических свойств такой тип почв наиболее пригоден для возделывания овощей.
Площадь опытной делянки 6,3 м², площадь учетной делянки - 5,6 м². Учет урожая проводился поделяночно. Расположение систематическое, повторность трехкратная. Расчетная густота стояния растений составила 400450 тыс. шт/га. Схема опыта по фонам питания: 1. Контроль - без удобрений; 2. $\mathrm{N}_{120} \mathrm{P}_{60} \mathrm{~K}_{180}$ (расчетная доза на $50 \mathrm{~T} /$ га); 3. $\mathrm{N}_{240} \mathrm{P}_{120} \mathrm{~K}_{360}$ (двойная доза).

Виды удобрений, применяемых в опыте: азофоска (д.в. NPK $16: 16: 16)$, аммиачная селитра (д.в. $\mathrm{N}-34 \%$ ), хлористый калий (д.в. К $\mathrm{O}$ $60 \%)$. Количество удобрений рассчитывалось согласно схеме опыта по фонам питания и по процентному содержанию действующего вещества.

Обработка экспериментальных данных проведена с использованием метода дисперсионного анализа.

Семена свеклы столовой начинают прорастать при температуpe 3-4 ${ }^{\circ} \mathrm{C}$, оптимальная температура $-20^{\circ} \mathrm{C}$. Растения данной культуры отличаются низкой засухоустойчивостью и требуют повышенного увлажнения, особенно в период интенсивного нарастания корнеплода. Наиболее благоприятные погодные условия для роста и развития растений свеклы столовой складывались в периоды вегетации 2014-2017 годов. В этот период среднемесячная температура воздуха за вегетационный период (май-сентябрь) незначительно отличалась от среднемноголетних значений. Показатели атмосферных осадков за этот период были на уровне среднемноголетних показателей. Вегетационные периоды 2014-2017 годов характеризовались как теплые и влажные.

В 2018 году выпадение осадков было меньше чем в 2017, а в июле и августе практически не было дождя. В том же году был очень теплый май, среднемесячная температура составляла днем $-21,3{ }^{\circ} \mathrm{C}$ и ночью -

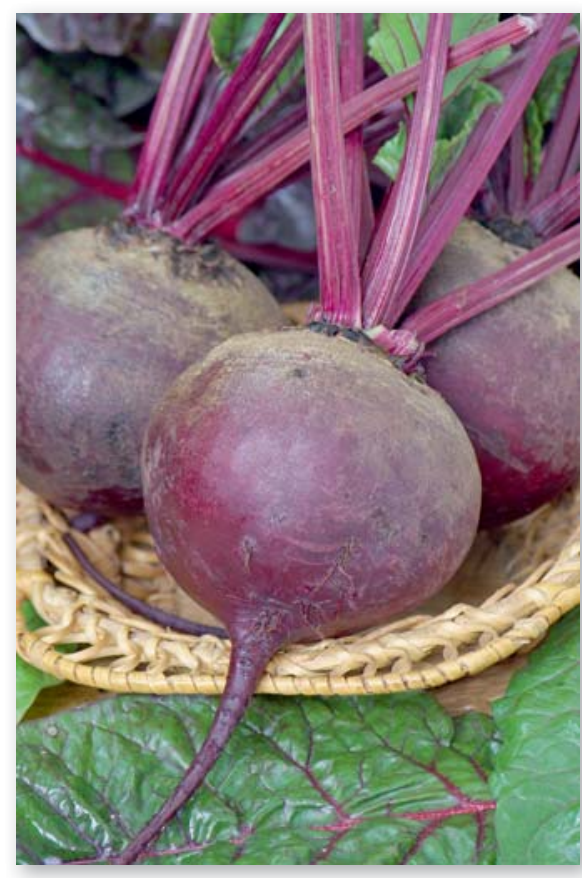

Сорт Русская односемянная

$16,3^{\circ} \mathrm{C}$. Все летние месяцы были теплыми и солнечными, средняя дневная температура июля и августа $25^{\circ} \mathrm{C}$, ночная $-20^{\circ} \mathrm{C}$.

Особенность погодных условий 2019 года - неравномерное выпадение осадков, что повлияло на время прорастания семян. Во время посева в третьей декаде мая выпало всего лишь $14,7 \%$ осадков по отношению к среднемноголетнему показателю. Наибольшее их количество пришлось на вторые декады июля и августа.

Недостаток влаги в период вегетации компенсировали поливами методом дождевания, поддерживая НВ на уровне 75-80\%.

\section{Результаты исследований}

Общая урожайность у сортов на фоне без удобрений изменялась от 36,5 (Мулатка) до 47,9 т/га (Славянка).

Влияние удобрений на урожайность и товарность свеклы столовой, 2014-2019 годы

\begin{tabular}{|c|c|c|c|c|c|c|c|c|c|c|c|c|}
\hline \multirow{3}{*}{ Сорт } & \multicolumn{4}{|c|}{ Без удобрений } & \multicolumn{4}{|c|}{ NPK } & \multicolumn{4}{|c|}{ 2NPK } \\
\hline & \multicolumn{2}{|c|}{ урожайность } & \multicolumn{2}{|c|}{ товарность } & \multicolumn{2}{|c|}{ урожайность } & \multicolumn{2}{|c|}{ товарность } & \multicolumn{2}{|c|}{ урожайность } & \multicolumn{2}{|c|}{ товарность } \\
\hline & т/га & $\mathrm{C}_{\mathrm{v}}$ & $\%$ & $\mathrm{C}_{\mathrm{v}}$ & т/га & $\mathrm{C}_{\mathrm{v}}$ & $\%$ & $\mathrm{C}_{\mathrm{v}}$ & т/га & $\mathrm{C}_{\mathrm{v}}$ & $\%$ & $\mathrm{C}_{\mathrm{v}}$ \\
\hline Креолка* & 37,93 & 17,76 & 85,57 & 8,06 & 44,00 & 30,47 & 87,13 & 10,43 & 58,60 & 16,73 & 84,93 & 15,19 \\
\hline Мулатка & 36,46 & 33,90 & 81,08 & 8,97 & 47,63 & 25,34 & 81,70 & 9,39 & 45,28 & 23,66 & 89,05 & 7,42 \\
\hline Русская односемянная & 42,55 & 19,97 & 86,75 & 7,07 & 49,43 & 22,92 & 89,82 & 4,26 & 46,95 & 14,33 & 84,80 & 10,63 \\
\hline Славянка & 47,87 & 39,51 & 83,90 & 13,95 & 53,95 & 27,89 & 83,95 & 10,02 & 52,22 & 16,35 & 84,08 & 7,51 \\
\hline Смуглянка & 42,07 & 35,20 & 81,58 & 15,58 & 54,35 & 27,77 & 81,60 & 24,09 & 48,68 & 17,83 & 87,48 & 11,16 \\
\hline Эфиопка* & 42,63 & 48,34 & 83,33 & 9,32 & 48,30 & 13,15 & 85,70 & 7,87 & 46,10 & 13,17 & 88,63 & 2,87 \\
\hline $\mathrm{HCP}_{05}$ & 4,23 & & & & 4,16 & & & & 5,28 & & & \\
\hline
\end{tabular}


Товарность у всех образцов составила свыше 80\%. Коэффициент вариации, показывающий изменение признака по годам, указывает на незначительное варьирование товарности у сортов с округлой формой корнеплода (CV менее 10\%). Наиболее подвержена изменению от условий года на фоне без удобрений общая урожайность, особенно у сортов Эфиопка и Славянка. Внесение рекомендуемой дозы минеральных удобрений позволило повысить общую урожайность, в среднем по сортам, на 8 т/га, или 20,3\%, не снизив товарность продукции (табл.). Наиболее отзывчивы на минеральные удобрения в рекомендуемой дозе оказались сорта Мулатка (+33,1\%) и Смуглянка (+29\%). Коэффициент вариации урожайности в данном варианте снизился, в среднем, на 10\%, что свидетельствует о нивелировании (сглаживании) погодных условий наданный показательпри внесении удобрений. Варьирование общей урожайности в данном варианте значительно повысилось лишь у сорта Креолка $\left(C_{v}=30,5\right)$. Товарность продукции при внесении удобрений увеличи- лась у сортов Креолка, Русская односемянная и Эфиопка на 2-3\%.

Внесение повышенных доз минеральных удобрений не повлекло за собой увеличение урожайности культуры. Общая урожайность сортов Мулатка, Русская односемянная, Славянка, Смуглянка и Эфиопка несколько снизилась по сравнению с вариантом на рекомендуемой дозе удобрений. Максимальное повышение общей урожайности и наибольшая отзывчивость на удобрения отмечено у сорта Креолка - 58,6 т/га, что составляет $154 \%$ от урожайности к варианту без внесения удобрений. Следует отметить, что у сортов Русская односемянная, Славянка и Смуглянка одновременно с общей урожайностью понизился и коэффициент вариации. То есть на повышенном фоне минеральных удобрений можно гарантированно получать потенциально возможный урожай сортов, незначительно изменяющийся от условий года. Максимальная товарность продукции в данном варианте получена у сортов Мулатка, Смуглянка и Эфиопка.

\section{Библиографический список}

1.Тимакова Л.Н., Лудилов В.А., Елизаров О.А Отечественные сорта столовой свеклы не хуже зарубежных // Картофель и овощи. 2011. №2. С. 2.

2.Буренин В.И. К проблеме церкоспороустойчивости сахарной свеклы (задачи селекции и исходный материал) // Сахарная свекла. 2018. №10. С. 2-5.

3.Евдокимова Л.Н. Оценка исходного материала свеклы столовой на адаптивность и выровненность корнеплода: автореф. дис. ... канд. с.-х. наук. М.: ВНИИО, 2004. 25 с.

4.Арустамов С.С., Соколов В.С., Кокоев Н.Ш. Неизменный лидер // Картофель и овощи. 2020. №2. С.16-19. https://doi. org/10.25630/PAV.2020.18.2.003

5.Бакланова О.В. и др. Отечественные сорта и гибриды для торговых сетей // Картофель и овощи. 2018. №10. C. 2-7. https:// doi.org/10.25630/PAV.2018.10.18441

6.Сортоиспытание новых сортов свеклы столовой на различных фонах минерального питания / Н.А. Фильрозе, Л.Н. Тимакова, В.А. Борисов, М.А. Долгополова // Картофель и овощи. 2018. №10. С. 22-24. https://doi.org/10.25630/PAV.2018.10.18445

7.Борисов В.А., Литвинов С.С., Романова А.В. Качество и лежкость овощей. М., 2003. 625 с.

8.Борисов В.А. Система удобрений овощных культур. М.: Росагропромиздат, 2016. 394 с

\section{Выводы}

Наибольшая прибавка урожая (12,5-33,1\%) получена на аллювиальных луговых почвах Московской области при рекомендуемой дозе внесения минеральных удобрений $\mathrm{N}_{120} \mathrm{P}_{60} \mathrm{~K}_{180}$ у сортов свеклы столовой Мулатка, Русская односемянная, Славянка, Смуглянка и Эфиопка. Сорт Креолка показал наибольшую урожайность при повышенной норме удобрений $\mathrm{N}_{240} \mathrm{P}_{120} \mathrm{~K}_{360}$.

Товарность сортов Агрохолдинга «Поиск» превышает $80 \%$ и увеличивается на 2-8\% с внесением удобрений.

Выращивание свеклы столовой с применением удобрений не только повышает урожайность культуры, но и уменьшает вариабельность ее по годам.

Сорта свеклы столовой с округлой формой корнеплода Креолка, Мулатка, Русская односемянная и Эфиопка подходят для крупнотоварного производства, где используется высокий уровень агротехники.

\section{References}

1.Timakova L.N., Ludilov V.A., Yelizarov O.A Domestic cultivars of cabbage are not worse than foreign ones. Potato and vegetables. 2011.No2. P. 2. (In Russ.).

2.Burenin V.I. Sugar beet resistance to cercosporosis (breeding tasks and initial material). Sugar beet. 2018. No10. Pp. 2-5 (In Russ.).

3.Yevdokimova L.N. Initial material assessment of red beet on adaptivity and uniformity: abstract Cand. Sci (Agr.). Moscow: ARRIVG, 2004. 25 p. (In Russ.).

4.Arustamov S.S., Sokolov V.S., Kokoyev N.SH. A constant leader. Potato and vegetables. 2020. No2. Pp.16-19 https://doi. org/10.25630/PAV.2020.18.2.003 (In Russ.).

5.Baklanova O.V. et al. Domestic cultivars and hybrids to retailers. Potato and vegetables. 2018. No10. Pp. 2-7 https://doi. org/10.25630/PAV.2018.10.18441 (In Russ.).

6.Variety testing of new varieties of red beet on different backgrounds of mineral nutrition / N.A. Filroze, L.N. Timakova, V.A. Borisov, M.A. Dolgopolova. Potato and vegetables. 2018. No10. Pp. 22-24 https://doi.org/10.25630/PAV.2018.10.18445 (In Russ.).

7.Borisov V.A., Litvinov S.S., Romanova A.V. Quality and storageability of vegetables. Moscow, 2003. 625 p. (In Russ.).

8.Borisov V.A. Fertilizer system for vegetable crops. Moscow: Rosagropromizdat, 2016. 394 p. (In Russ.).

\section{Об авторах}

Тимакова Любовь Николаевна, канд. с-х. наук, с.н.с. отдела селекции и семеноводства, ВНИИО - филиал ФГБНУ ФНЦО, селекционер Агрохолдинга «Поиск». E-mail: ljubovtimakova@rambler.ru

Борисов Валерий Александрович, доктор с-х. наук, професcop, г.н.с. отдела земледелия и агрохимии, ВНИИО - филиал ФГБНУ ФНЦО. E-mail: valeri.borisov.39@mail.ru

Фильрозе Николай Айтжанович, н.с. отдела земледелия и агрохимии, ВНИИО - филиал ФГБНУ ФНЦО. E-mail: Suburban_Chevrolet@mail.ru

\section{Author details}

Timakova L.N., Cand. Sci. (Agr.), senior research fellow of department of breeding and seed growing, All-Russian Research Institute of Vegetable Growing - branch of Federal Scientific Centre of Vegetable Growing (ARRIVG - branch of FSBSI FSCVG). E-mail: ljubovtimakova@rambler.ru

Borisov V.A., Doctor Sci. (Agr.), professor, chief research fellow of the department of agriculture and agricultural chemistry, ARRIVG - branch of FSBSI FSCVG. E-mail: valeri.borisov.39@mail.ru

Filroze N.A, research fellow of department of agriculture and agricultural chemistry, ARRIVG - branch of FSBSI FSCVG. E-mail: Suburban_Chevrolet@mail.ru 